\title{
Tables
}

1. Classification of mothers' initial reactions, reactions at the time of their departure from the hospital, and decisions regarding the disposition of children

2. Classification of thalidomide children wearing prostheses according to site of major limb-deficiency, and past and present placement

3. Mothers' perceptions of the children's appearance while wearing prostheses

4. Mothers' perceptions of the children's level of independence while wearing prostheses

5. Mothers' judgment of their ability to caress children wearing prostheses

6. Mothers' estimation of children's daily wearing time of prostheses

7. Hypothetical rating of visual appearance, functional utility, and tactile qualities of hands, feet, and prostheses 



\section{Abnormality and Normality}

The Mothering of Thalidomide Children 
